\title{
Low-cost experimental application of real-time kinematic positioning for increasing the benefits in cereal crops
}

\author{
Abdelhamid Tayebi*, Josefa Gómez, Marián Fernández, Francisco Sáez de Adana, \\ Oscar Gutiérrez \\ (Computer Science Department, University of Alcalá, Alcalá de Henares 28801, Spain)
}

\begin{abstract}
Traditional agriculture is facing several challenges worldwide such as increased population growth, rapid forestry and urbanization, resource scarcity, climate change, environmental pollution, competition among different markets. Hence, farmers need to improve productivity in order to maintain the output level. This study attempted to evaluate the benefits of using Real-Time Kinematic (RTK) positioning in precision agriculture through a series of real measurements carried out when farming cereals. All farming management actions involved in the cereal crop process (raise fallow, plow, sow, fertilize, mow, and harvest) have been done using an automatic guidance system that has reduced costs. A reduction of $20 \%$ has been quantified in the fuel, the amount of fertilizer, the labor costs and the hours of work. Consequently, the environmental impact has been also reduced. An inexpensive system consisting of a reference base station near the field and a mobile unit mounted on the test vehicle has been installed in order to increase the benefits in cereal crops. Global Navigation Satellite System (GNSS) systems including Global Positioning System (GPS), GLONASS, Galileo and Beidou have been used in the analysis. This research serves as a practical guide to implementing a low-cost guidance system to achieve best management practice.
\end{abstract}

Keywords: real-time kinematic, low-cost, positioning, benefits, guidance system, cereal

DOI: $10.25165 /$ j.ijabe.20211403.5812

Citation: Tayebi A, Gomez J, Fernández M, de Adana F S, Gutiérrez O. Low-cost experimental application of real-time kinematic positioning for increasing the benefits in cereal crops. Int J Agric \& Biol Eng, 2021; 14(3): 194-199.

\section{Introduction}

With the increasingly competitive agriculture, the need to make the management of the activity more efficient means that nowadays farmers have to incorporate different tools of precision agriculture in their daily routine. Precision agriculture is a farming management concept based on satellite positioning data, information technology, remote sensing technology, robotics, etc., with the aim of saving costs, reducing environmental impacts and producing more and better outputs.

The evolutions of vehicle guidance, auto-steering and controlled traffic farming systems have been possible thanks to the Global Navigation Satellite System (GNSS). GNSS includes the Global Positioning System (GPS), GLONASS, Galileo, Beidou and other regional systems. GPS is accurate to $1 \mathrm{~m}$, therefore, it is not considered suitable for the types of machine control considered in this work. On the other hand, Differential Global Positioning System (DGPS) provides improved location accuracy. The main drawbacks of DGPS are lack of repeatability and satellite drift. In contrast to DGPS, Real-Time Kinematic also considers the second

Received date: $2020-03-30 \quad$ Accepted date: 2021-04-19

Biographies: Josefa Gómez, PhD, Associate Professor, research interests: RTK positioning, radio propagation, Email: josefa.gomezp@uah.es; Marián Fernández, $\mathrm{PhD}$, Associate Professor, research interests: computational electromagnetics and precision agriculture, Email: marian.fernandez@uah.es; Francisco Sáez de Adana, $\mathrm{PhD}$, Associate Professor, research interests: computational electromagnetics and radio propagation, Email: kiko.saez@uah.es; Oscar Gutiérrez, PhD, Associate Professor, research interests: radio propagation prediction models and precision agriculture, Email: oscar.gutierrez@uah.es.

*Corresponding author: Abdelhamid Tayebi, PhD, Associate Professor, research interests: antennas, radio propagation. Computer Science Department, University of Alcalá, Alcalá de Henares 28801, Spain. Tel: +34-918856675, Email: hamid.tayebi@uah.es. transmission frequency of the satellites and offers a positioning accuracy within 10 to $50 \mathrm{~mm}$. This is enough for the real-time control of farm vehicles. Hence, the automatic guidance system implemented in this study is based on RTK as the unique positioning sensor. Evidently, like the other techniques based on GNSS, RTK is independent of the size and geographical characteristics of the field as well as independent of daytime, weather and field activity.

Automated guidance systems enable vehicles to drive along predetermined tracks accurately, while clearly reducing fatigue and errors by the driver, since he/she can focus on the main functions of the machinery. The most common problem of the driver is overlap or missing between two adjacent tracks with large implements. And this problem is even worse under low light conditions. Thus, guidance systems permit an extension of the workday whilst increasing the work speed and providing timeliness of activities. Other potential benefits are related to efficiency and productivity, which are maintained at the same level during the whole workday.

The most significant benefit mentioned above is the reduction of the overlapping, since it is directly related to the cost of fuel, fertilizers, seeds, agrochemicals and workforce. A high percentage of the savings from guidance systems arise from saved fertilizer and spray resources. Sustainable agricultural production systems are, then, possible thanks to the adoption of precision farming techniques. The environmental benefits are difficult to measure but the risk to environmental pollution can be clearly reduced since the number of chemicals saved can be seen as chemicals are not required and not taken by crops and also not released into the environment. According to the state of the art, not only the economic impact of technology applied to agriculture can be found in several studies ${ }^{[1-7]}$, but also the reduction of 
environmental impact ${ }^{[8-10]}$. For example, the report was presented by O'Connor et al. ${ }^{[11]}$ indicates that farmers in the United States have relied so much on GPS. They estimate that the agricultural industry could lose $\$ 15.1$ billion across maize, soybean, spring wheat, cotton, and peanuts if an ill-timed outage were to occur.

Also, Ortiz et al. ${ }^{[12]}$ found that the use of an RTK auto-steer guidance system for peanut digging operations not only resulted in minimized yield losses but also increased net returns.

On the other hand, a comparative study ${ }^{[13]}$ was carried out by the University of Córdoba in Spain on wheat sowing, with two different approaches: sowing traditionally without applying GPS techniques and sowing with an automatic guidance system based on RTK GPS. Results showed input saving percentages of $6.16 \%$ and $6.31 \%$ during two consecutive years. In a different experimental work $^{[14]}$, it has been demonstrated that the saving would be $23.5 € / \mathrm{hm}^{2}$ only in sowing and fertilizer applications. Those cost savings were due to the lower overlap in headlands and up to $17 \%$ less use of pesticides. Knight et al. ${ }^{[15]}$ used information about a farm to analyze the profitability of investing in RTK guidance technology. Two equipment guidance systems were evaluated and both systems earned more than $8 \%$ on capital invested. According to Reference [16], the economic benefits of guiding systems in the United Kingdom for a $500 \mathrm{hm}^{2}$ farm were at least at $2.24 € / \mathrm{hm}^{2}$. Benefits grow if more complex systems are adopted, which leads to additional returns of $18-45 € / \mathrm{hm}^{2}$ for winter wheat. A different study that was carried out by Frascarelli ${ }^{[17]}$ on maize crops showed that the cost of using agricultural machines decreased $29.37 € / \mathrm{hm}^{2}$ when replacing manual tractor guidance with an automatic one.

Another relevant consideration when analyzing the benefits of applying precision farming is the size of the field. Some studies $^{[18,19]}$ have analyzed this aspect across the European Union indicating that guidance systems are beneficial if they are adopted on fields between 100 and $300 \mathrm{hm}^{2}$. In the case under study, the tests have been carried out in a $50 \mathrm{hm}^{2}$ field providing satisfactory results. However, it is expected that higher benefits should be achieved when adopting the proposed system in wider fields. An analysis of the impact of the size of the farm on system profitability was explored by Batte et al. ${ }^{[20]}$ That study suggested that benefits of input savings were substantial when the patterns became more complex due to non-rectangular fields and due to the presence of waterways, drainage ditches or similar obstructions.

To date, only very few researchers ${ }^{[21-23]}$ have focused on RTK applications with low-cost receivers. The objective of this research is to evaluate the economic, practical and environmental benefits of using a low-cost system based on RTK GNSS through a series of real measurements carried out when farming cereals. A cost reduction of $20 \%$ has been quantified considering the liters of fuel, the amount of fertilizer, labor costs and the hours of work.

The study is organized as follows: the first part deals with the hardware and software required to implementing the proposed guidance system; the second part describes the experimental tests that have been carried out in order to achieve the best accuracy. The third part includes measurements when carrying out different activities and the last part contains the concluding remarks and future work.

\section{Materials and methods}

A row-crop tractor John Deere 7810 (John Deere, USA) was used to carry out the tests. The vehicle was equipped with the mobile unit of the guidance system known as a rover, which comprised a receiving antenna, a navigation software installed in a tablet BQ Tesla W8, a hub, an Ublox NEO-M8T module, an encoder, a steering wheel engine, a motor controller board, an inertial measurement unit and some cables and adapters. As mentioned before, the RTK was used to obtain the real-time position and the driving direction of the vehicle. Hence, the implementation required a mobile part on the tractor and a fixed part as a local base station, which sent correction signals to the receiving antenna. Low-cost antennas communicated via a radio link were used in both parts of the system. Figure 1 shows a diagram of the automatic guidance system.
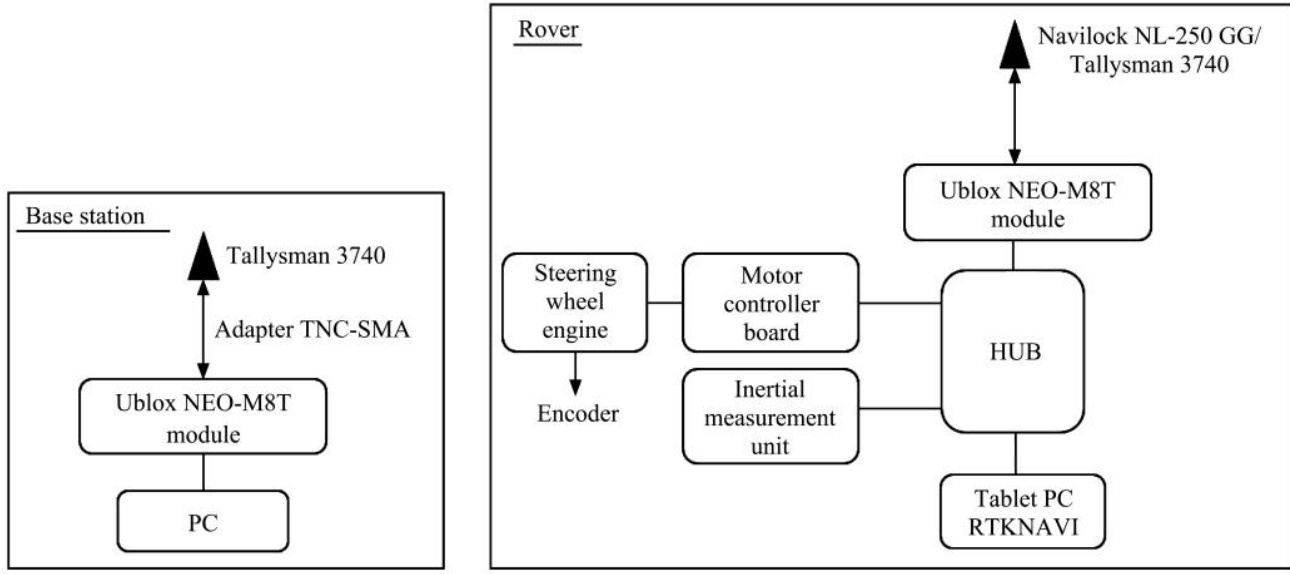

Figure 1 Diagram of the automatic guidance system

The reference station antenna was connected to a computer by means of a U-blox NEO-M8T module (U-Blox, Swiss). The STRSVR program was installed in that computer in order to interconnect the antenna of the base station and the antenna mounted on the vehicle by establishing data communication links, since they were placed in different sites. Regarding the base station location, it has to be chosen to minimize multipath and interference no further than $10 \mathrm{~km}$ away from the field.

Farmers have a different alternative to take benefit of the
GNSS technology: subscription services. These are mainly operated by distributors of precision agriculture equipment, such as the John Deere RTK Network, but also some private companies are involved (SmartNet ${ }^{[24]}$ ). There are also farmers' associations that have set up their own network with public aid, and public administrations that manage GNSS networks and offer free access to their citizens. That is the case of Spain, where the tests have been carried out. The Spanish GNSS network is the result of the collaboration between both regional and national institutions. It 
relies on data from more than 200 permanent GNSS stations distributed throughout the state and uses data emitted by satellites of several constellations such as GPS, GLONASS and GALILEO. Fortunately, Spanish farmers can reduce the total equipment cost of the guidance system by taking advantage of this free service.

Finally, a type of additional navigation software called Cerea was installed in the tablet connected to the receiving antenna. The program has the following features: autorotation in headers, slope compensation, contour registration, parcel measurement, time estimation, map creation, 3D or $2 \mathrm{D}$ view of the guidance, indication for visual guidance on screen, and day or night mode. In addition, Cerea enables the setup of the following pattern options: parallel straight guidance, parallel curved guidance, guided in two parallel directions and guided in a parallel pivot.

\section{Experimental tests}

Real-time tests were carried out in Castilla la Mancha (Spain) on flat ground $\left(38^{\circ} 44^{\prime} 14^{\prime \prime} \mathrm{N}, 3^{\circ} 0^{\prime} 53^{\prime \prime} \mathrm{W}\right)$ to evaluate the reliability of the guidance system. Four different tests were carried out in order to find the configuration that provided the best accuracy. The more accurate the guidance system is, the more benefits are obtained mainly due to the lack of overlapping areas in each pass and less non-processed areas. Thus, less fuel is needed, fewer working hours are spent and less resource is wasted. In the tests, the reference was not always a straight line, since the field had a non-rectangular shape. In order to reduce the curvature at the end of each pass, the pattern left an intermediate work line between each pass (see Figure 2). The vehicle velocity was set to a constant value in all tests because the terrain was flat and homogeneous. Typically, the velocity was set to $4-5 \mathrm{~km} / \mathrm{h}$ when ploughing or harvesting and to $12-15 \mathrm{~km} / \mathrm{h}$ when fertilizing or spraying.

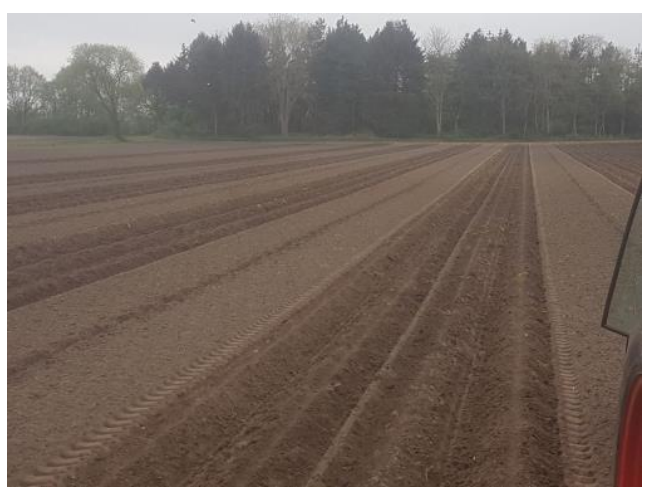

Figure 2 Field area where the experimental tests have been carried out

\subsection{Test 1}

Firstly, a smart antenna (Novatel Ag-start) in autonomous mode was used on the rover. It consists of an integrated L1 GPS+GLONASS receiver and antenna in a single rugged housing without the need of having an Internet connection. According to the specifications, the smart antenna provided the sub-meter position accuracy. The tests were carried out when ploughing, and it was found that the accuracy decreased when the time between two consecutive passes was longer than $20 \mathrm{~min}$. That is, after that time or when the activity stops, it is necessary to correct the pattern in order to continue working with optimal performance. 3.2 Test 2

In this case, the Novatel Ag-start antenna was connected to the Spanish GNSS network by using RTKLIB which is the open-source program package for standard and precise positioning with GNSS.
This connection required a previous registration to obtain a user and password to access the service. However, since the nearest base station was $80 \mathrm{~km}$ far away, the accuracy did not improve because it depended on the distance between the rover and the base station.

\subsection{Test 3}

The lesson learned in the second test was that the reference base station needed to be nearer. Therefore, a local base station was installed near the field. A low-cost multi-constellation antenna (Tallysman 3740) was placed there together with a Ublox NEO-M8T module. The Tallysman 3740 covered the GPS L1, GLONASS G1, Galileo E1, BeiDou B1 and SBAS (WAAS, EGNOS \& MSAS) frequency bands (1557 to $1606 \mathrm{MHz})$. According to the specifications, it provided a truly circular response over its entire bandwidth thereby producing superior multipath signal rejection resulting in higher accuracy of position and timing. Regarding U-blox NEO-M8T, it is an ultra-small and light device that delivers high integrity, precision timing in demanding applications worldwide. It supports GPS/QZSS, GLONASS, BeiDou and SBAS. Its enhanced sensitivity and concurrent dual-constellation reception extend coverage and integrity to challenging signal environments. In addition, the survey-in and fixed-position navigation reduce timing jitter, even at low signal levels, and enable synchronization to be maintained with as few as one single satellite in view. A remarkable feature is that both items (the multi-constellation antenna and the U-blox NEO-M8T) are low-cost devices. In order to use the RTKLIB programs in the base station, the router ports had to be opened. The IP address of the base station was used to setup the communication link and connect the rover with the base station. The antenna used on the rover was the same as the previous tests, the Novatel Ag-start GPS+GLONASS. The achieved accuracy, in this case, was better than that in the previous cases independently on the time between consecutive passes. The most outstanding problem was a drift of about $200 \mathrm{~mm}$ between the patterns when there was a loss of signal from the receiver or due to a failure in the internet connection.

\subsection{Test 4}

In this case, a multi-constellation antenna (Tallysman 2710) similar to the one installed in the base station (Tallysman 3740) was mounted on the rover instead of using the Novatel Ag-start. A second U-blox NEO-M8T module was also necessary to be used on the rover. Finally, this was the option that has provided the best results, even after a weekend in between. This configuration assured the correct offset between adjacent passes, without overlapping and failures. Figures 3 and 4 show the pattern $7 \mathrm{~km}$ far from the base station after a weekend without working. It can be seen that the trajectory followed by the vehicle coincides with the pattern pre-established by the auto-guidance system.

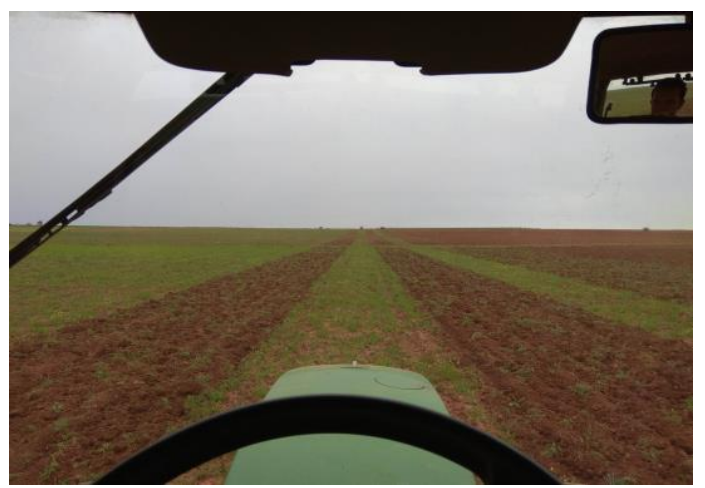

Figure 3 Pattern followed by the vehicle 


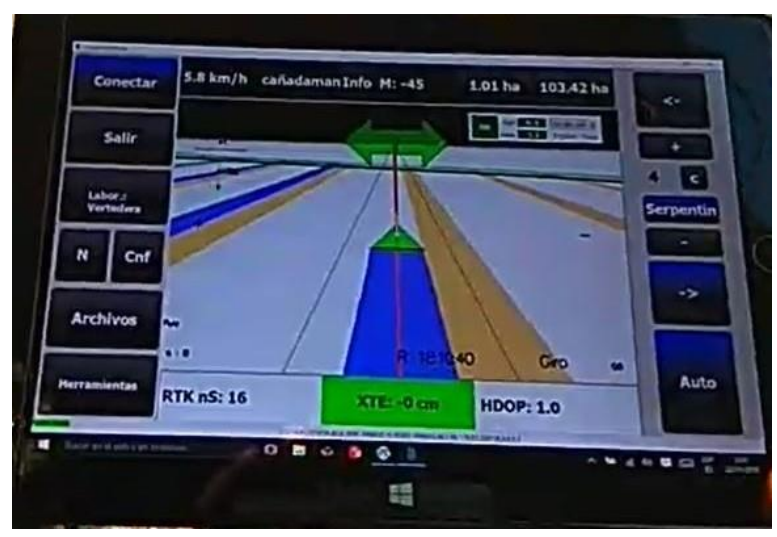

Figure 4 Screen of the Cerea program

The problem that has been found is the need to rely on the Internet for the use of these modules because it has not been possible to operate with them in the autonomous mode. The Novatel Ag-start has a correction data processor, which makes it possible to be used autonomously, while the Tallysman-Ublox set requires a source for processing corrections, the RTKLIB, which makes it difficult to be used autonomously.

\section{Measurements}

The following results were obtained using the installation described in test 4 . All the activities were carried out in the same field, located in Castilla la Mancha (Spain), whose size is $50 \mathrm{hm}^{2}$. Before beginning, the Cerea program needed to capture the contour of the field in order to provide the patterns and to compute the estimated time to finish the activity. Once the contour was processed, it could be used for all the different activities that needed to be done in that field. The contour was captured when the vehicle started and finished at the same point by enabling the capture contour option.

\subsection{Activity 1}

The first activity consisted of smoothing the land to protect the seeds from adverse weather conditions (see Figure 5).

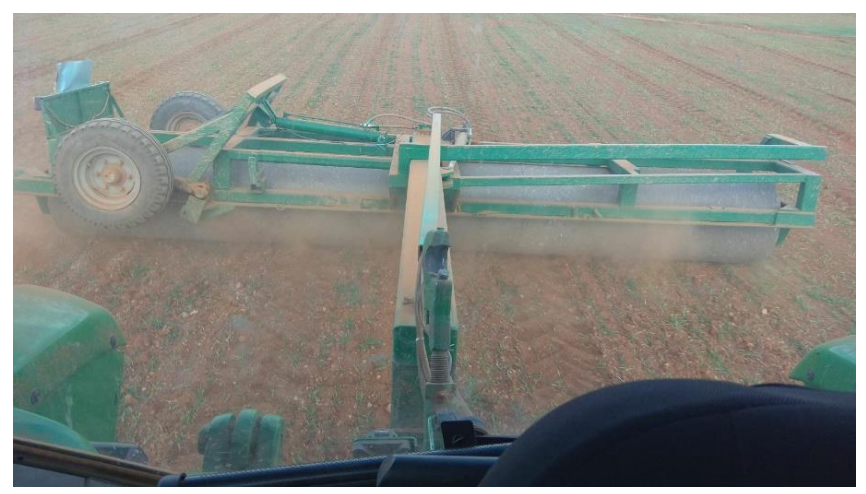

Figure 5 Roller at the back part of the tractor

The roller was $5.6 \mathrm{~m}$ long but the passes were conducted every $5.5 \mathrm{~m}$ so that there were no areas without flattening. In the automatic guidance system, the control unit manages the steering wheel, the gearbox, and the connected implement. Therefore, no driver is needed while some activities such as smoothing the land are being carried out. The error measured, also called pattern deviation, was $100 \mathrm{~mm}$ with the guidance system and around 200-300 mm without using it. This implied not only a small amount of saved fuel (around 2\%) but also 18 work hours less to pay to the driver. Figure 6 shows how the pattern deviation has been measured. Initially, the auto-guidance program shows a pre-established trajectory to be followed by the tractor. However, the actual trajectory followed by the tractor is not exactly the same as the initial pre-established trajectory. This means that the current position of the vehicle was not the adequate position according to the master pattern indicated by the auto-guidance $\operatorname{program}^{[25]}$. The error measured has been calculated as the root mean square error of the drifts in each pass.

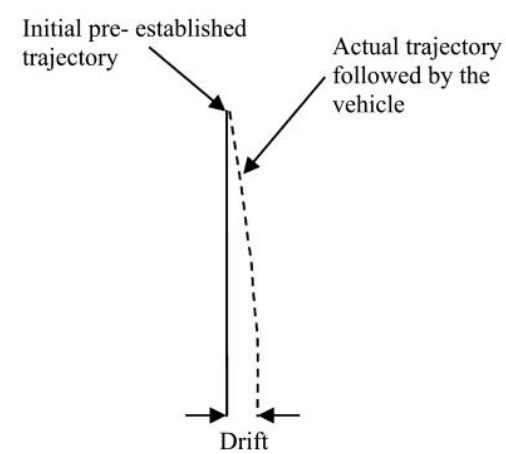

Note: The drift occurs when the initial trajectory pre-established by the auto-guidance program is not precisely followed by the vehicle

Figure 6 Schematic diagram of the drift

\subsection{Activity 2}

This activity consisted of making furrows in the land with the plow, in order to remove the herbs to prepare the ground for the next planting. The implement was $4.85 \mathrm{~m}$ long and the base station was $8 \mathrm{~km}$ far from the rover when the activity started. A comparison was made to evaluate the benefits of using the auto-guidance system. First, the auto-guidance system was used. The estimated time to finish the activity was $17 \mathrm{~h}$, but it took $20 \mathrm{~h}$ to finish. A high accuracy was observed in this case, since the missing distance between passes of the pattern was $20-30 \mathrm{~mm}$. Without using the guidance system, this same activity took $22 \mathrm{~h}$ because an extra $2 \mathrm{~h}$ were needed to maneuver when turning at the ends. In this case, the precision dramatically decreased, since the real distance between consecutive passes was $200 \mathrm{~mm}$ in one direction and $200 \mathrm{~mm}$ in the opposite direction (400 $\mathrm{mm}$ per turn). This fact implied a variation of the precision of $0.82 \%$ in each round, which means that, approximately, one full pass is lost per every 100 turns. In this case, around $3 \%$ of the fuel and 22 work hours were saved.

\subsection{Activity 3}

This activity consisted of ploughing the land. In this activity, the measurements were focused on fuel consumption instead of the pattern deviation. The implement was $5 \mathrm{~m}$ long and the base station was $8.43 \mathrm{~km}$ far away from the rover. The fuel consumption during 7 hours and 40 minutes working without the guidance system was $111 \mathrm{~L}$. The same activity carried out with the guidance system took $7 \mathrm{~h}$ and the fuel consumption was reduced to $100 \mathrm{~L}$. Thus, $9 \%$ of the fuel and 7 work hours were saved in this activity.

\subsection{Activity 4}

This activity consisted of spraying crops. The implement used to spread the agrochemicals was $16 \mathrm{~m}$ long. This activity is impossible to carry out accurately without the support of a guidance system, since it is quite hard for the operator to guide such a big implement (see Figure 7). The guidance system allowed a homogenous distribution of the phytosanitary treatments and fertilizers, which mean better use of the products and a more homogeneous distribution in the land. Moreover, the guidance system recorded the sprayed/fertilized areas. When a section of the sprayer boom overlapped one of the areas that had already been sprayed, that section was automatically turned off, and then turned 
back on when it re-entered an area that had not yet been sprayed. This automation is useful on point rows, curved rows, and even at the end of each pass. The reduction in overlapped/double-dosed areas saves fertilizers and pesticides, fuel and time, and operator fatigue. According to the auto-guidance program, this implied a reduction of $5 \%$ in fertilizers. 6 work hours and $3 \%$ in fuel were also saved using the auto-guidance system.

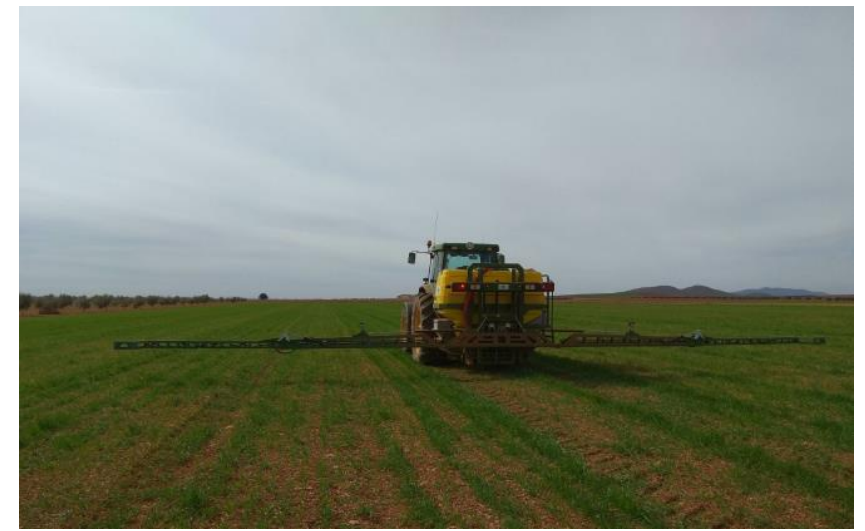

Figure 7 Fertilization activity using a $16 \mathrm{~m}$ long implement

Table 1 summarizes the measurements that were carried out during activities 1 to 4 . Good results have been obtained regarding pattern deviation, work hours, fuel consumption and fertilizers consumption. These results corroborate what was found in previous studies ${ }^{[10,13-20]}$. For example, experimental results presented in Reference [10] showed a fuel reduction of around $8 \%$. The use of automatic guidance systems based on low-cost devices increases the benefits and improves farm profitability.

Table 1 Summary of the measurements that were carried out during the activities 1 to 4

\begin{tabular}{lcccc}
\hline \multicolumn{1}{c}{ Measured items } & \multicolumn{4}{c}{ Activity } \\
\cline { 2 - 5 } & 1 & 2 & 3 & 4 \\
\hline $\begin{array}{l}\text { Pattern deviation without guidance } \\
\text { system/mm }\end{array}$ & $200-300$ & 200 & - & - \\
Pattern deviation with guidance system/mm & 100 & $20-30$ & & \\
Work hours less to pay/h & 18 & 22 & 7 & 6 \\
Percentage of fuel consumption reduction & $2 \%$ & $3 \%$ & $9 \%$ & $3 \%$ \\
Fertilizers & - & - & - & $5 \%$ \\
\hline
\end{tabular}

\section{Conclusions}

Nowadays, farmers must address problems related to agricultural production, seeking to minimize the environmental impact, and maximize business profit and the ergonomic comfortability of the driver. The purpose of this work was to evaluate the potential economic benefits that can be obtained when applying low-cost techniques of precision agriculture for cereal production.

The proposed RTK guidance system has saved resources mainly by reducing overlaps between passes during cultivation, fertilizing or harvesting (less wastage of fuel), matching input doses to local needs (less wastage of fertilizers, seeds, and sprays) and improving timeliness. Thus, the application of concrete precision agriculture techniques in the field under study has clearly provided environmental benefits. Concretely, the crop output was the same as applying traditional agriculture, but the liters of fuel, the amount of fertilizer, labor costs and the hours of work have been reduced around $20 \%$. That percentage also includes the increase in the machinery value at replacement due to having worked fewer hours.

It is hoped that the proposed study can serve as a guide to allow farmers to decide if an investment in low-cost GNSS devices will improve their farm profitability by reducing the cost of fuel, fertilizers, seeds, agrochemicals and workforce.

\section{Acknowledgements}

This work was supported by the Project of University of Alcalá (Grant No. CCG2016/EXP-055).

\section{[References]}

[1] Chavas J P. A cost approach to economic analysis under state-contingent production uncertainty. American Journal of Agricultural Economics, 2008; 90(2): 435-446.

[2] Takács-György K, Óbudai E. Economic aspects of an agricultural innovation - precision crop production. In: Applied Studies in Agribusiness and Commerce (APSTRACT). Budapest: Agroinform Publishing House, 2012; pp.51-57. doi: 10.19041/Apstract/2012/1-2/6.

[3] Swinton S M. Economics of site specific weed management. Weed Science, 2005; 53(2): 259-263.

[4] Godwin R J, Richards T E, Wood G A, Welsh J P, Knight S M. An economic analysis of the potential for precision farming in UK cereal production. Biosystems Engineering, 2003; 84(4): 533-545.

[5] Gandonou J M, Dillon C R. Precision timing and spatial allocation of economic fertilizer application. In: South Agricultural Economics Association Annual Meeting, Mobile. Alabama, 2007; 34955.

[6] Lencsés E. Advantages and disadvantages of precision farming technology from economic aspect. Annals of the Polish Association of Agricultural and Agribusiness Economists, 2009; 6: 83-87.

[7] Lencsés E, Takács-György K. Changes in costs of precision nutrition depending on crop rotation. In: Applied Studies in Agribusiness and Commerce (APSTRACT). Budapest: Agroinform Publishing House, 2009; 3(3-4): 59-64. doi: 10.19041/Apstract/2009/3-4/13.

[8] Jongeneel R, Polman N, Slangen L. Cost-benefit analysis of the Dutch nature conservation policy: Direct, indirect effects and transaction costs of the ecological main structure in Netherlands. In: 12th Congress of the European Association of Agricultural Economists (EAAE). Ghent, 2008.

[9] Magda S, Magda R, Marselek S. Sustainable development of the rural economy. In: Applied Studies in Agribusiness and Commerce (APSTRACT). Budapest: Agroinform Publishing House, 2009; 3(5-6): 31-36. doi: 10.19041/Apstract/2009/5-6/5.

[10] Kelc D, Stajnko D, Berk P, Rakun J, Vindiš P, Lakota M. Reduction of environmental pollution by using RTK-navigation in soil cultivation. Int J Agric \& Biol Eng, 2019; 12(5): 173-178.

[11] O'Connor A C, Gallaher M P, Clark-Sutton K, Lapidus D, Oliver Z T, Scott T J, et al. Economic benefits of the global positioning system (GPS) RTI International, 2019; Report No. 0215471. doi: 10.13140/ RG.2.2.12336.20487

[12] Ortiz B, Balkcom K, Duzy L, van Santen E, Hartzog D. Evaluation of agronomic and economic benefits of using RTK-GPS-based auto-steer guidance systems for peanut digging operations. Precision Agriculture, 2013; 14(4): 357-375. doi: 10.1007/s11119-012-9297-y.

[13] Pérez M, Aguiera J, Gil J. Desarrollo, evaluación y análisis de técnicas de agricultura de precisión para la optimización de insumos en cultivos característicos del valle del Guadalquivir. Doctoral dissertation. Córdoba: Universidad de Córdoba, 2007; 176p. (in Spanish)

[14] Luck J D, Pitla S K, Shearer S A, Mueller T G, Dillon C R, Fulton J P, et al Potential for pesticide and nutrient saving via map-based automatic boom section control of spray nozzles. Computers and Electronics in Agriculture, 2010; 70(1): 19-26.

[15] Knight B, Malcolm B. A whole-farm investment analysis of some precision agriculture technologies. In: 51st Annual Conference of the Australasian Agricultural and Resource Economics Society, Queenstown, 2007; 46p

[16] Precision agriculture: an opportunity for EU farmers- potential support with the CAP 2014-2020. Directorate-general for internal policies. Policy department B. Structural and cohesion policies. European Parliament. 
[17] Frascarelli A. Valutazione economica dell'agricoltura di precisione (Economic evaluation of precisión agriculture, in Italian). Agricoltura di Precisione. Metodi e Tecnologie per Migliorare l'Efficienza e la Sostenibilità dei Sistemi Colturali (Precision Agriculture. Methods and Technologies for Improving the Efficiency and Sustainability of Crop Systems, in Italian). Bologna: Edagricole, 2016. pp.213-228. (in Italian)

[18] Knight S, Miller P, Orson J. An up-to-date cost/benefit analysis of precision farming techniques to guide growers of cereals and oilseeds. HGCA Research Review, 2009; 35(6): 2820. doi: 10.1118/1.2962165.

[19] Lawes R A, Robertson M J. Whole farm implications on the application of variable rate technology to every cropped field. Field Crops Research, 2011; 124(2): 142-148

[20] Batte M T, Reza M. The economics of precision guidance with auto-boom control for farmer-owned agricultural sprayers. Computers and Electronics in Agriculture, 2006; 53(1): 28-44.
[21] Takasu T, Yasuda A. Development of the low-cost RTK-GPS receiver with an open source program package RTKLIB. In: Proceedings of the International Symposium on GPS/GNSS, Jeju, Korea, 2009.

[22] Yin X, Wang Y X, Chen Y L, Jin C Q, Du J. Development of autonomous navigation controller for agricultural vehicles. Int J Agric \& Biol Eng, 2020; 13(4): 70-76.

[23] Catania P, Comparetti A, Febo P, Morello G, Orlando S, Roma E, et al Positioning accuracy comparison of GNSS receivers used for mapping and guidance of agricultural machines. Agronomy, 2020; 10(7): $924 . \quad$ doi: 10.3390/agronomy10070924.

[24] SmartNet HxGN. Available: https://hxgnsmartnet.com/en-gb/. Accessed on [2020-03-21].

[25] Ospina R, Noguchi N. Improved inclination correction method applied to the guidance system of agricultural vehicles. Int J Agric \& Biol Eng, 2020; 13(6): 183-194. 